\title{
EMOWARS: \\ INTERACTIVE GAME INPUT MENGGUNAKAN EKSPRESI WAJAH
}

\author{
Andry Chowanda \\ Computer Science Department, School of Computer Science, Binus University \\ Jl. K.H. Syahdan No. 9, Palmerah, Jakarta Barat 11480 \\ achowanda@binus.edu
}

\begin{abstract}
Research in the affective game has received attention from the research communities over this lustrum. As a crucial aspect of a game, emotions play an important role in user experience as well as to emphasize the user's emotions state on game design. This will improve the user's interactivity while they playing the game. This research aims to discuss and analyze whether emotions can replace traditional user game inputs (keyboard, mouse, and others). The methodology used in this research is divided into two main phases: game design and facial expression recognition. The results of this research indicate that users preferred to use a traditional input such as mouse. Moreover, user's interactivities with game are still slightly low. However, this is a great opportunity for researchers in affective game with a more interactive game play as well as rich and complex story. Hopefully this will improve the user affective state and emotions in game. The results of this research imply that happy emotion obtains $78 \%$ of detection, meanwhile the anger emotion has the lowest detection of 44.4\%. Moreover, users prefer mouse and FER (face expression recognition) as the best input for this game.
\end{abstract}

Keywords: affective game, facial expression recognition, interactive game input, affective computing

\begin{abstract}
ABSTRAK
Riset dibidang affective game telah menerima perhatian dari kalangan peneliti akhir lustrum ini. Hal ini karena emosi merupakan aspek yang krusial pada game. Emosi juga memainkan peran penting dalam user experience. Menekankan emosi pada game design akan meningkatkan interakifitas user dalam memainkan game. Penelitian ini bertujuan untuk membahas dan menganalisis apakah emosi dapat menggantikan user game input tradisional seperti keyboard, mouse, serta input lainnya serta apakah menggunakan emosi sebagai user game input dapat meningkatkan interakifitas user dalam memainkan game. Metodologi penelitian yang diusulkan terbagi menjadi dua tahapan utama, yaitu game design dan facial expression recognition. Hasil evaluasi ini menunjukkan bahwa user yang masih memilih mouse (input tradisional) masih tinggi, serta user masih merasa belum terlalu interaktif dengan game dengan menggunakan input emosi. Namun, hal ini merupakan kesempatan yang besar untuk riset di bidang affective game dengan game play yang lebih interaktif dan kaya akan cerita sehingga akan meningkatkan affective state dan emosi user dalam bermain game. Berdasarkan hasil evaluasi yang dilakukan pada tahap akhir didapatkan dari segi ketepatan, emosi happy yang paling tinggi tingkat ketepatannya (78\%) sedangkan emosi anger memiliki tingkat tidak terdeteksi paling tinggi yaitu $44.4 \%$. Di sisi lain, preferensi input game yang dipilih user kebanyakan adalah mouse dan FER (face expression recognition) untuk tipe game ini.
\end{abstract}

Kata kunci: permainan afektif, pengenalan ekspresi wajah, input game interaktif, komputasi afektif 


\section{PENDAHULUAN}

Emosi merupakan aspek yang krusial pada game. Emosi juga memainkan peran penting dalam user experience serta dengan menekankan emosi pada game design akan meningkatkan interakifitas user dalam memainkan game (Gilleade and Dix, 2004).

Komputer memang tidak akan dapat mengenal emosi seperti manusia. Tetapi berkat riset yang dilakukan semenjak beberapa decade yang lalu, para peneliti khususnya dibidang computer science dapat "memberikan" kemampuan untuk mengenal emosi kepada komputer melalui sensor seperti kamera, mikrofon, dll. Komputer dapat mengenal emosi dari facial expression recognition, pergerakan tubuh, serta fitur dari suara seperti pitch, $f 0$, dll. Beberapa algoritma yang digunakan antara lain: neural networks, hidden markov chain, bayesian networks dan support vector machine.

Yang dimaksudkan dengan facial expression adalah perubahan yang terjadi pada wajah dalam menanggapi keadaan emosi internal seseorang, baik dalam personal maupun dalam kondisi social. Riset dibidang facial expression analysis telah menjadi topic penelitian yang menarik bagi ilmuan di bidang behavioural science sejak tahun 1872 oleh Darwin (1872) sampai sekarang. Telah banyak penelitian yang dilakukan pada bidang ini, salah satunya yang dikenal secara universal adalah riset mengenai FACS (facial action coding system) oleh Ekman, et al., (2002). Mereka melakukan coding terhadap perubahan yang terjadi pada wajah ketika seseorang menanggapi situasi yang memicu emosi internal seseorang. Mereka membagi region wajah menjadi dua bagian yaitu atas dan bawah. Kemudian mereka mulai memberikan penomoran pada masing-masing aksi yang dipicu oleh pergerakan otot-otot wajah. Gambar 1(a) menggambarkan penomoran otot wajah bagian atas sedangkan Gambar 1(b) menggambarkan penomoran otot wajah bagian bawah.

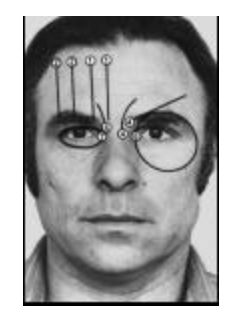

(a)

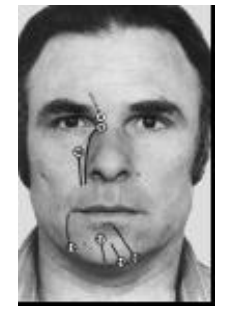

(b)

Gambar 1 Face muscular action (Ekman, 2002)

Setiap nomor atau/dan kombinasi nomor yang dihasilkan oleh otot wajah dapat menginterpretasikan kondisi emosi seseorang. Ekman mengklasifikasikannya menjadi enam emosi dasar manusia, yaitu: happy, angry, sad, surprised, disgusted, scared serta neutral, yaitu kondisi di mana tidak ada satu pun otot wajah yang diaktifkan. Hasil penelitian Ekman, et al., mengungkapkan bahwa enam emosi dasar manusia bersifat universal yang berarti tidak berdasarkan ras, daerah, kondisi sosial, atau apa pun. Gambaran besar mengenai pengenalan wajah menurut FACS dapat dilihat pada Gambar 2.

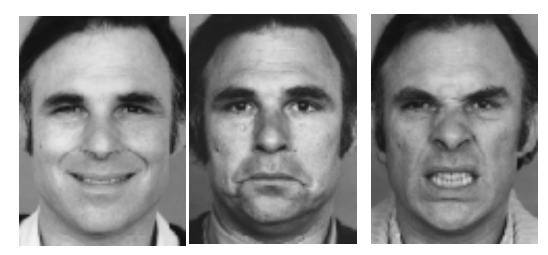

Gambar 2 Action unit dari kiri ke kanan: happy (AU12+AU25), sad (AU15+AU17), angry (AU9+AU16+AU25) (Ekman, et al., 2002). 
FACS dapat digunakan sebagai model untuk facial expression recognition. Facial expression recognition terbagi menjadi tiga tahapan, yaitu face acquisition, facial features extraction, dan facial expression recognition (Ying-Li, et al., 2011). Gambaran proses facial expression recognition dilihat pada Gambar 3.

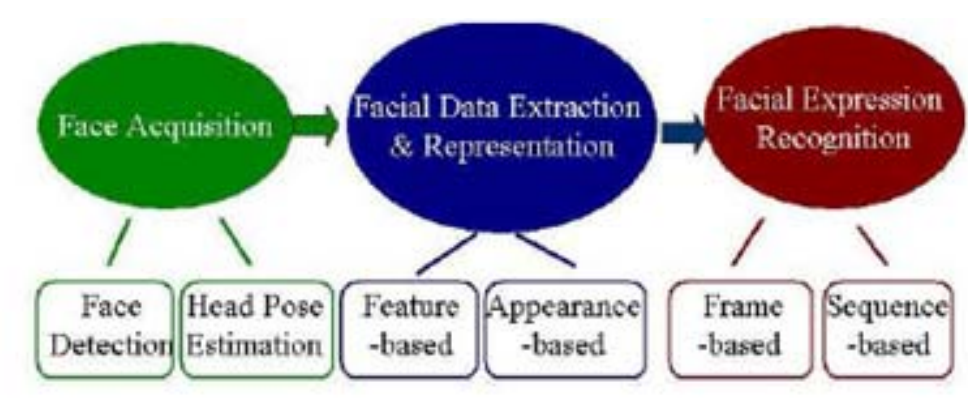

Gambar 3 Tahapan face expression recognition (Ying-Li, et al., 2011)

Riset dibidang affective game merupakan turunan dari riset affective computing di bidang game. Istilah affective computing mulai diperkenalkan secara global di dunia akademia sejak tahun 1997 oleh Picard. Pada bukunya, Picard (1997) mendefinisikan affective computing sebagai "computing that relates to, arises from, or deliberately influences emotions". Riset di bidang ini fokus pada tiga sub-topik, yaitu: (1) automatic analysis of emotion, yang berfokus pada pengenalan dan analisis emosi secara automatic melalui sensor seperti kamera, mikrofon, atau sensor-sensor lainnya; (2) emotion conceptual modelling, yang berfokus pada permodelan emosi dengan menggunakan teori emosi dari bidang psikologi, biologi, dan ilmu komputer kemudian diterapkan sebagai model untuk computer agent seperti robot, emobodied computer agents, dan lainnya; (3) emotion synthesis, yang fokus pada sintesis emosi pada computer agents di mana agents menampilkan spektrum yang luas dari emosi buatan (sintesis) yang dihasilkan isyarat perilaku nonverbal Pada sub-topik ini fokus pada bagaimana sintetis emosi yang dihasilkan mampu menyampaikan sinyal sosial yang memunculkan persepsi sosial yang diinginkan kepada user (Pantic, et al., 2011).

Affect-focused game design adalah sebuah pendekatan baru di game design yang menekankan affective state (contoh emosi) dari user. Aspek lain dari desain game juga dipengaruhi, terutama aspek visual dan pendengaran dari permainan, yang juga sangat mempengaruhi affective state (contoh emosi) dari user. Sisi emosi dari user juga dapat dimasukkan ke dalam berbagai aspek permainan, termasuk user interface dari game dan dinamika lingkungan game, pilihan tugas permainan atau situasi yang diberikan kepada pemain (misalnya, tugas lebih mudah untuk membangun kepercayaan diri, tugas yang sulit untuk menantang), dan integrasi mereka dengan inappearance dan perilaku karakter permainan atau avatar para user.

Terdapat beberapa research questions yang menarik untuk diinvestigasi yaitu: (1) apakah emosi dapat menjadi user input pada game? (2) sensor apa saja yang effektif digunakan sebagai alat untuk menangkap dan menganalisis emosi dari user dan digunakan untuk game? (3) model apa yang efektif digunakan sebagai model untuk game agents atau Non-Playable Characters? (4) bagaimana sistesis emosi yang dihasilkan oleh game agents atau Non-Playable Characters mampu menyampaikan sinyal sosial yang memunculkan persepsi sosial yang diinginkan kepada user.

Penelitian ini bertujuan untuk membahas dan menganalisis apakah emosi dapat menggantikan user game input tradisional seperti keyboard, mouse, serta input lainnya serta apakah menggunakan emosi sebagai user game input dapat meningkatkan interakifitas user dalam memainkan game seperti yang dikemukakan oleh Gilleade and Dix (2004). 


\section{METODE}

Metodologi penelitian yang diusulkan terbagi menjadi dua tahapan utama, yaitu tahapan game design dan tahapan facial expression recognition (Gambar 4).
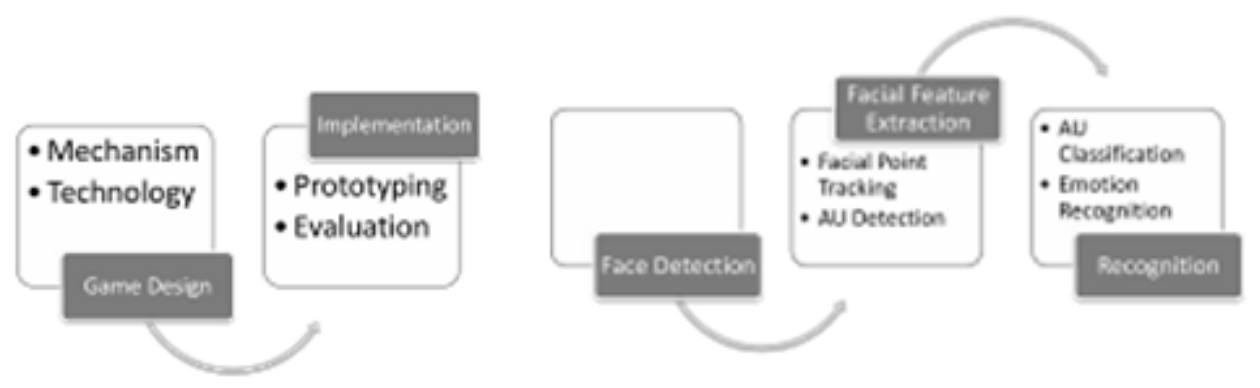

Gambar 4 Metodologi penelitian yang diusulkan

\section{Game Design}

Tahapan ini bertujuan untuk mendesign game yang menggunakan emosi sebagai input game. Pada tahapan ini dilakukan design untuk mekanisme/rules yang akan berlaku di game ini, serta akan membahas mengenai teknologi yang akan digunakan pada game ini di mana akan berkaitan dengan tahapan selanjutnya yaitu facial expression recognition. Output yang diharapkan dari tahapan ini adalah game yang siap untuk dievaluasi berdasarkan tujuan yang telah dikemukakan pada bagian pendahuluan.

Pada sub-tahapan implementasi, akan dilakukan evaluasi terhadap game yang akan fokus menganalisis apakah emosi dapat menggantikan user game input yang tradisional seperti keyboard, mouse, serta input lainnya serta apakah dengan menggunakan emosi sebagai user game input dapat meningkatkan interakifitas user dalam memainkan game.

\section{Facial Expression Recognition}

Tahapan ini bertujuan untuk mendesign facial expression recognition sebagai technology input yang akan digunakan pada tahapan pertama. Pada tahapan ini penelitian ini hanya focus kepada algoritma yang digunakan pada tahapan recognition saja yang dijabarkan pada hasil dan pembahasan sub-bagian AU Detection, AU Classification, dan emotion recognition. Tahapan-tahapan lainnya yang dibutuhkan menggunakan algoritma yang sudah dikembangkan oleh peneliti yang lain. Face Detection menggunakan Viola-Jones face detector (Viola dan Jones, 2004) yang menggunakan AdaBoost sebagai classifier-nya. Facial point tracking menggunakan algoritma fiducial facial point detector yang dikembangkan oleh Vukadinovic, dan Pantic (2005) menggunakan gabungan Gabor-filter dan GentleBoost.

\section{HASIL DAN PEMBAHASAN}

\section{Game Design}

Game play pada game ini sangat simple, yaitu seperti bermain batu gunting dan kertas. Hanya 
saja pada game ini digunakan magic fire, thunder, dan water element. Fire akan mengalahkan thunder, tapi kalah terhadap water. Thunder akan mengalahkan water tapi kalah terhadap fire, dan yang terakhir water akan mengalahkan fire tapi kalah terhadap thunder. Gambaran mengenai permainan ini dapat dilihat pada Gambar 5.

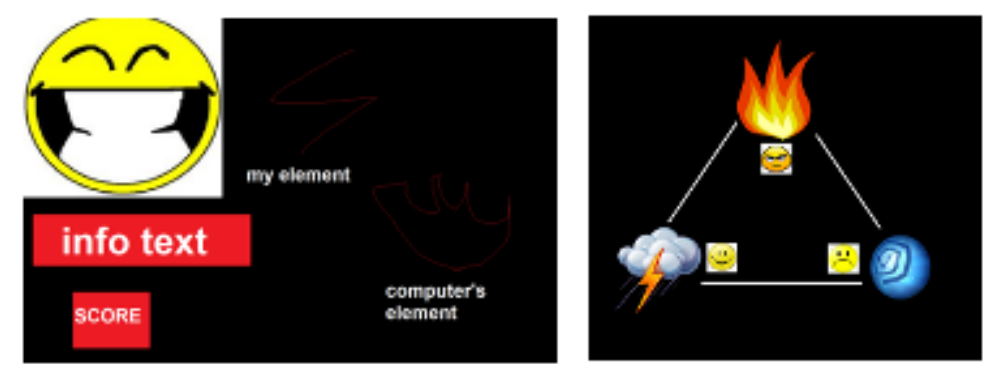

Gambar 5 Perancangan permainan

Pada Gambar 5 sebelah kiri, smiley berwarna kuning menunjukan gambar wajah yang ditangkap oleh kamera. Di bawah wajah terdapat text berupa info dan score user. Sedangkan pada gambar sebelah kanan terdapat gambar element yang dihasilkan berdasarkan input, yaitu fire untuk emosi angry, water untuk emosi sad, dan thunder untuk emosi happy. Komputer akan melakukan randomize untuk menghasilkan elemen fire, water, atau thunder.

Teknologi yang akan digunakan untuk membangun game ini adalah desktop dengan menggunakan operating system Windows 732 bit, dengan kamera 2 MP sebagai video input untuk facial expression recognition. Input dalam game ini menggunakan emosi seperti yang sudah dijelaskan pada bagian mechanism.

\section{Face Detection}

Karena fokus utama pada penelitian ini bukan face detection, module face detection pada penelitian ini menggunakan Viola-Jones face detector (Viola, Jones, 2004) yang menggunakan AdaBoost sebagai classifier-nya.

\section{Facial Point Tracking}

Karena fokus utama pada penelitian ini bukan facial point tracking, module facial point tracking pada penelitian ini menggunakan algoritma fiducial facial point detector yang dikembangkan oleh (Vukadinovic, Pantic, 2005) dengan menggunakan gabungan Gabor-filter dan GentleBoost. facial point tracking bertujuan untuk medapatkan titik-titik di wajah yang digunakan untuk Facial Point Detector untuk action unit yang dilakukan setiap otot di wajah. Gambar 6 menggambarkan gambaran besar titik-titik yang digunakan untuk facial point tracking dan detector pada algoritma yang digunakan oleh Vukadinovic dan Pantic (2005). 

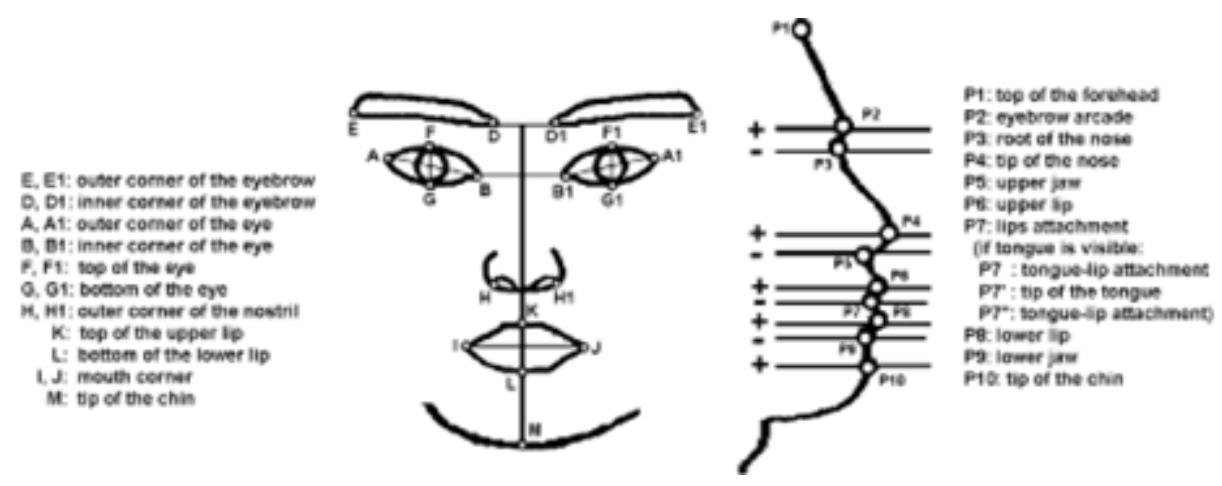

Gambar 6 Facial point detector (Vukadinovic dan Pantic, 2005)

\section{AU Detection}

Action Unit (AU) detection bertujuan untuk mendeteksi pergerakan titik-titik di wajah yang dipicu oleh pergerakan otot diwajah dalam menanggapi keadaan emosi internal seseorang. Titik-titik yang berhasil dideteksi pada tahapan sebelumnya, akan dilakukan tracking dan dilihat perubahan pada titik-titik tersebut. Perubahan pada titik-titik tersebut mengadopsi sistem FACS (Ekman, et al., 2002). Output dari tahapan ini berupa kumpulan vektor yang berisi perubahan titik-titik, yang akan diproses pada tahapan AU Classification sehingga dapat ditentukan klasifikasi dari emosi.

\section{AU Classification}

Dari tahapan sebelumnya, didapat data berupa kumpulan vektor yang dapat diproses dengan menggunakan SVM (support vector machine) classification. Pada akhir setiap atribut dari vektor ditempatkan untuk menentukan kategori emosi. Setelah matriks memiliki parameter pelatihan data harus diatur untuk melatih classifier SVM. SVM classification akan diimplementasikan dengan bantuan library libsvm di mana peneliti tidak perlu membuat dari awal fungsi-fungsi yang akan digunakan untuk proses image training. Peneliti hanya perlu melakukan modifikasi data untuk disesuaikan dengan penelitian ini. Librari libsvm adalah software yang berlisensi GPL yang dikembangkan oleh Chih-Chung and Chih-Jen (2011) . Perintah pada libsvm yang telah dimodifikasi dengan bahasa c++ kemudian di gabungkan dengan librari openCV sebagai alat untuk memproses gambar.

void Svm::train(const data *d); untuk training data baru.

void Svm::predict(const data* d); untuk memprediksi data yang sudah ada kemudian dikembalikan ke classifier.

float Svm::parameteroptimisation(const maclet::data * d); untuk melakukan optimasi parameter data yang digunakan.

int Svm::save(path fn); const untuk menyimpan hasil training dari data baru

int Svm::load(path fn); untuk me-load data yang telah ada.

Classifier akan disimpan dalam file digunakan untuk memprediksi emosi pada gambar baru.

\section{Emotion Recognition}

Tahapan terakhir adalah emotion recognition. Setelah mendapatkan nilai dari tahapan $A U$ Classification, nilai tersebut ditransformasi menjadi sebuah emosi dengan menggunakan FACS (Ekman, et al., 2002). Untuk sementara modul ini hanya dapat memprediksi emosi happy, angry, sad, dan neutral. Contoh: Angry dapat dideteksi dari AU9 (lower face) dan AU25 (upper face). Sistem AU pada FACS dapat dilihat pada Gambar 7. 


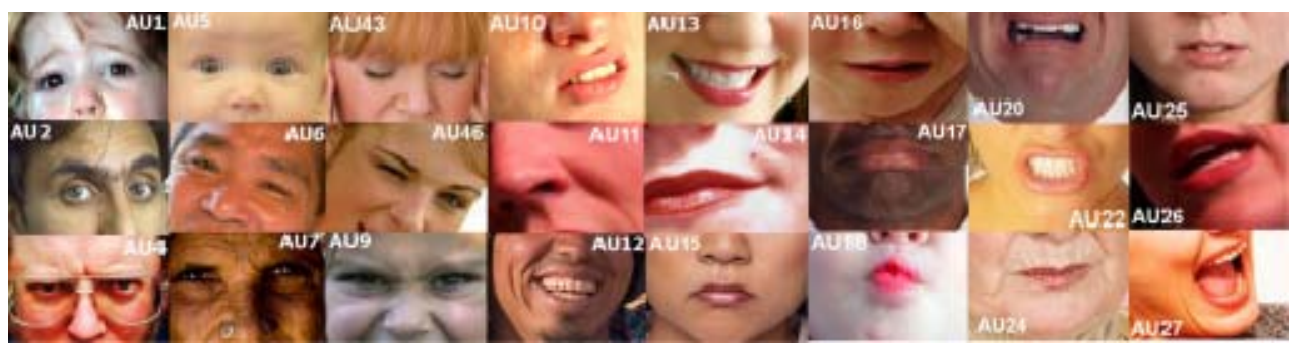

Gambar 7 FACS

\section{Implementation and Evaluation}

Tahapan ini bertujuan untuk melakukan implementasi dan evaluasi terhadap game yang akan fokus menganalisis apakah emosi dapat menggantikan user game input yang tradisional seperti keyboard, mouse, serta input lainnya serta apakah dengan menggunakan emosi sebagai user game input dapat meningkatkan interakifitas user dalam memainkan game. Hasil implementasi dapat dilihat pada Gambar 10.
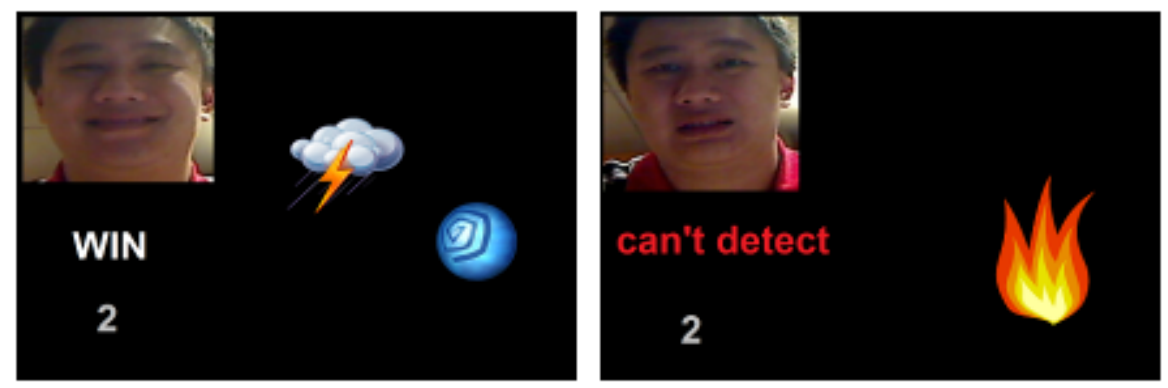

Gambar 10 Implementasi game

Evaluasi dilakukan terhadap 9 peserta yang mencoba terlebih dahulu memainkan sebanyak minimal lima ronde permainan. Peneliti juga termasuk ke dalam sembilan peserta yang melakukan evaluasi game ini. Ada tiga aspek utama yang dievaluasi, yaitu ketepatan deteksi emosi, preferensi input (tradisional vs facial expression recognition) dan tingkat interaktivitas user. Hasil dapat dilihat pada Tabel 1 dan Gambar 11.

Tabel 1Ketepatan Deteksi Emosi

\begin{tabular}{lllll}
\hline & happy & sad & angry & $\begin{array}{l}\text { tidak } \\
\text { terdetsi }\end{array}$ \\
\hline happy & $\mathbf{7 ( 7 7 . 8 \% )}$ & $2(22.2 \%)$ & $0(0.0 \%)$ & $0(0.0 \%)$ \\
\hline sad & $3(33.3 \%)$ & $\mathbf{3 ( 3 3 . 3 \% )}$ & $1(11.1 \%)$ & $2(22.2 \%)$ \\
\hline angry & $0(0.0 \%)$ & $2(22.2 \%)$ & $\mathbf{3 ( 3 3 . 3 \% )}$ & $4(44.4 \%)$ \\
\hline
\end{tabular}

Dapat dilihat dari tabel 1, dari segi ketepatan, emosi happy yang paling tinggi tingkat ketepatannya (78\%) dan emosi sad dan anger memiliki nilai yang sama yaitu 33.3\%. Namun emosi angry memiliki tingkat tidak terdeteksi paling tinggi yaitu $44.4 \%$. 

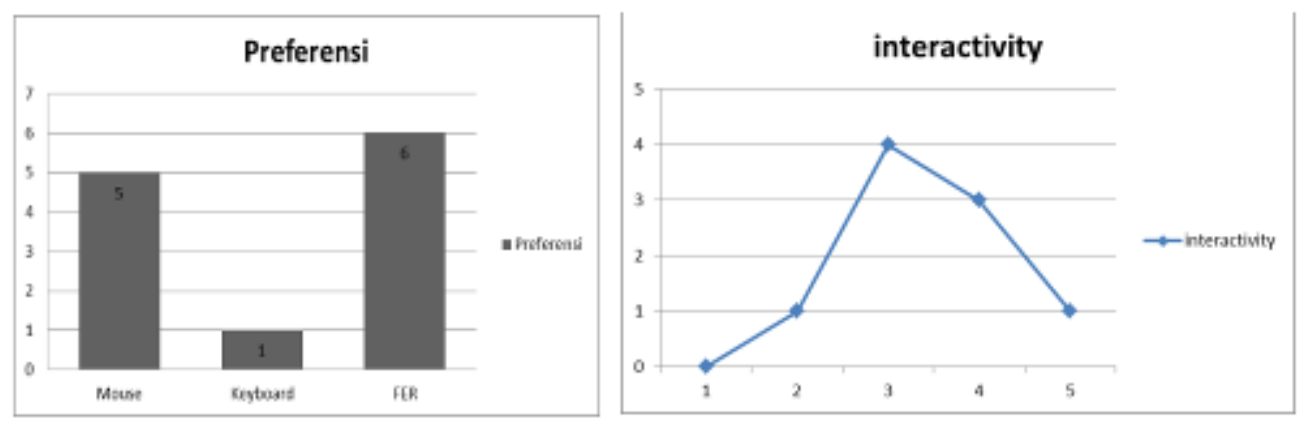

Gambar 11 Hasil evaluasi

Berdasarkan hasil pada Gambar 11, preferensi input game yang dipilih user kebanyakan adalah mouse dan FER (Face Expression Recognition) dalam tipe game ini. Untuk evaluasi ini, user dapat memilih satu/lebih preferensi. Di sisi lain, dalam segi tingkat interaktifitas user dalam game ini, mayoritas user memilih biasa saja (tingkat $=3$ sebanyak 4) dan lumayan interaktif (tingkat $=4$ sebanyak 3).

\section{PENUTUP}

Berdasarkan hasil evaluasi yang dilakukan pada tahap akhir didapatkan dari segi ketepatan, emosi happy yang paling tinggi tingkat ketepatannya (78\%) dan emosi sad dan anger memiliki nilai yang sama yaitu 33.3\%. Namun emosi angry memiliki tingkat tidak terdeteksi paling tinggi yaitu 44.4\%. Di sisi lain, preferensi input game yang dipilih user kebanyakan adalah mouse dan FER (Face Expression Recognition) dalam tipe game ini. Serta, mayoritas user memilih biasa saja (tingkat $=3$ sebanyak 4) dan lumayan interaktif (tingkat = 4 sebanyak 3) dalam hal interaktifitas. Hasil evaluasi ini menunjukkan bahwa user yang masih memilih mouse (input tradisional) masih tinggi, serta user masih merasa belum terlalu interaktif dengan game dengan menggunakan input emosi. Namun, hal ini merupakan kesempatan yang besar untuk riset di bidang affective game dengan game play yang lebih interaktif dan kaya akan cerita sehingga akan meningkatkan affective state dan emosi user dalam bermain game.

Saran untuk penelitian lebih lanjut adalah emosi sebagai input dapat diimplementasikan ke game play yang lebih kompleks seperti game RPG (Role Playing Game) di mana kaya akan konflik sehingga affective state (contoh emosi) akan lebih kaya, serta interaksi antara user dan NPC (NonPlayable Character) akan meningkat seiring dengan kompleksnya game play. Bagian/komponen facial expression recognition pada penelitian ini dapat digunakan ulang (re-useable) untuk penelitian selanjutnya sehingga pada penelitian selanjutnya dapat lebih fokus terhadap training data untuk face expression recognition dan pengembangan game design.

\section{DAFTAR PUSTAKA}

Chih-Chung, C., \& Chih-Jen, L. (2011). LIBSVM : a library for support vector machines. ACM Transactions on Intelligent Systems and Technology, 2:27:1-27:27, USA.

Darwin, C. (1965, 1872). The Expression of Emotions in Man and Animals. Chicago: University of Chicago Press. 
Ekman, P., Friesen., W., Hage, J. (2002). Facial Action Coding System: The Manual. Salt Lake City: Research Nexus division of Network Information Research Corporation.

Gilleade, K. M., \& Dix, A. (2004). Using Frustration in the Design of Adaptive Videogames. Singapore: ACW.

Pantic, M., Cowie, R., Derrico, F., Heylen, F., Mehu, M., Pelachaud, C., Poggi, I. , Schroeder, M., and Vin-Ciarelli, A. (2011). Agenda on Social Signal Processing Research. Europe: Europe 7th Framework Programme.

Picard, R. (1997). Affective Computing. Cambridge, MA: The MIT Press.

Schell, J. (2008). The Art of Game Design. Massachusetts: Morgan Kaufmann.

Viola, P., \& Jones, M. (2004). Robust real-time object detection. Int. J. Computer Vision.,57 (2), 137154, May 2004.

Vukadinovic, D., \& Pantic, M. (2005). Fully automatic facial feature point detection using Gabor feature based boosted features. IEEE Int. Conf. Syst., Man, Cybern., 2005, 1692-1698.

Ying-Li, T., Kanade, T., \& Cohn, J. (2011). Handbook of Face Recognition. London: Springer. 